\title{
Vendor Confidentiality Agreement
}

National Cancer Institute

\section{Source}

National Cancer Institute. Vendor Confidentiality Agreement. NCI Thesaurus. Code C115465.

A leg ally binding accord that inhibits the disclosure of information by an individual, or group of individuals, who are providing a service or product. 